\title{
Judicialização da Saúde: um estudo de caso de três tribunais brasileiros
}

\author{
The judicialization of health care: a case study \\ of three state courts in Brazil
}

Denise Vieira Travassos ${ }^{1}$

Raquel Conceição Ferreira ${ }^{1}$

Andréa Maria Duarte Vargas ${ }^{1}$

Rosa Núbia Vieira de Moura ${ }^{1}$

Elza Maria de Araújo Conceição ${ }^{1}$

Daniela de Freitas Marques ${ }^{2}$

Efigênia Ferreira e Ferreira ${ }^{1}$

${ }^{1}$ Departamento de

Odontologia Social e

Preventiva, Faculdade de

Odontologia, Universidade

Federal de Minas Gerais. Av.

Antonio Carlos 6627,

Pampulha. 31.270-901

Belo Horizonte MG Brasil.

detravassos@gmail.com

${ }^{2}$ Departamento de Direito

Penal, Faculdade de Direito,

UFMG.

\begin{abstract}
The scope of this study was to describe and compare records of the results of lawsuits filed in three Brazilian courts in cases involving the Unified Health System. A survey was made of the judgments listed on electronic sites of Courts of Justice in the states of Pernambuco, Rio Grande do Sul and Minas Gerais using a specific script. A total of 558 judgments was analyzed. There was a greater frequency of ordinary lawsuits (73.1\%). In the majority of cases, it was not possible to identify the economic situation of the plaintiff or the legal representative of the defendant (54.5\%). In cases where such identification was possible, a public defender was the most common (71.5\%). The cases were predominantly individual in all three states. There was a large number of requests for injunctions (83.8\%), which were almost always granted (91.2\%), with the allegation of urgency/emergency in almost all cases (98.8\%). The majority of decisions were favorable to the users of the public healthcare system (97.8\%). The decisions studied showed that the users sought to ensure their right to health individually, using the public authorities to file their lawsuit, but there is a perceived difference in posture between legal courts evaluated. There is a strong tendency of the judiciary to accept these requests.
\end{abstract}

Key words Right to health, Unified health system, Jurisprudence
Resumo O objetivo deste trabalho foi descrever e comparar registros de três tribunais brasileiros quanto às características e resultados das ações relacionadas ao Sistema Único de Saúde (SUS). Foi realizada pesquisa dos acórdãos nos sítios eletrônicos dos Tribunais de Justiça dos estados de Pernambuco, Rio Grande do Sul e Minas Gerais, utilizando-se roteiro próprio. Analisou-se 558 acórdãos. Houve maior frequência de ações ordinárias (73,1\%), na maior parte das decisões não foi possível verificar a situação econômico-financeira do demandante e o representante do autor (69,1\% e 54,5\%) Nas que foram possíveis, a defensoria pública foi mais frequente $(71,5)$, principalmente no Rio Grande do Sul (90,2\%). A titularidade das ações foi predominantemente individual nos três grupos. Houve grande número de pedidos liminares (83,8\%), quase sempre deferidos (91,2\%), com alegação de urgência/emergência em quase todos (98,8\%). A maioria das decisões foi favorável aos usuários (97,8\%). As decisões estudadas demonstraram que o usuário tem buscado de forma individual garantir seu direito à saúde, recorrendo ao próprio poder público para a propositura da ação, mas percebe-se uma diferença de postura jurídica entre os tribunais avaliados. Há uma forte tendência do Judiciário em acolher estas solicitações.

Palavras-chave Direito à Saúde, Sistema Único de Saúde, Jurisprudência 


\section{Introdução}

O conceito de saúde abrangente da Organização Mundial de Saúde (OMS, 1946) definido "como um estado de completo bem-estar físico, mental e social e não apenas a simples ausência de doenças e outros danos", foi determinante para o reconhecimento deste direito fundamental do ser humano, consolidando a concepção da necessidade de integração do indivíduo na sociedade ${ }^{1}$.

A saúde, assim considerada ${ }^{2}$, foi incluída como garantia aos povos pelos governos em tratados internacionais, em seu sentido abrangente ${ }^{3}$.

A Declaração Universal dos Direitos Humanos (1948) e o Protocolo sobre Direitos Econômicos, Sociais e Culturais (1988) consideraram a saúde condição indispensável à dignidade humana, com estreita relação com condições socioambientais, econômicas e obrigação do Estado para dar condições ao pleno exercício desses direitos².

$\mathrm{O}$ direito à saúde torna governos responsáveis pela prevenção, tratamento e controle de doenças e criação de condições para garantir acesso aos serviços de saúde. Em função dos direitos humanos (econômicos, sociais, culturais, civis e políticos) serem considerados interdependentes e indivisíveis, os governos são responsáveis por programar e implementar condições progressivas para garantir o direito à saúde, assim como aos demais direitos sociais 4 .

As Constituições brasileiras anteriores foram omissas em relação à garantia do direito à saúde. Apenas previam que cabia ao Estado cuidar da assistência pública e da prestação de assistência médica e hospitalar ao trabalhador filiado ao regime previdenciário. Este direito só foi contemplado na atual Constituição, 40 anos após a Declaração Universal dos Direitos Humanos ${ }^{5}$.

O Brasil tem um sistema de proteção dos direitos humanos que integra o ordenamento jurídico nacional e as proteções oferecidas pelas normas jurídicas de direito internacional ${ }^{6}$. A saúde foi eleita como direito extremamente relevante na Constituição Federal, pois o princípio da dignidade da pessoa humana é um dos fundamentos do Estado, assegurada ainda a inviolabilidade do direito à vida ${ }^{7}$.

Entretanto, como disposto em lei, todos têm direito à saúde, independente de raça, gênero, idade e classe social, mas isso muitas vezes não ocorre. Percebe-se que há uma grande insatisfação/descrença em relação ao Sistema Único de Saúde (SUS) $)^{5}$. Muitas vezes, o cidadão tem a sensação de não acolhimento de seus anseios por parte dos serviços de saúde, público ou privado, sensação que pode ser fundada na necessidade real ou percebida de sua própria saúde.

A compreensão da saúde varia de acordo com o indivíduo, suas crenças e valores, em função da causa de sua doença e a possibilidade de controle de sua situação estes fatores podem influenciar a adesão dos pacientes aos tratamentos propostos e a forma de utilização dos serviços de saúde 8 .

Há necessidade de buscar formas de tornar coerentes as leis positivadas e o sentimento da comunidade em relação ao direito. A norma jurídica preconiza um entendimento, de ser o direito à saúde universal, integral e gratuito, no entanto, as situações vividas pelos indivíduos caminham em sentindo oposto. Vivenciam-se constantes violações desses princípios, o que agrava as iniquidades do sistema de saúde?.

Em algumas situações, nas quais os usuários dos Sistemas de Saúde, público ou suplementar, ficam insatisfeitos pode haver o questionamento judicial das prestações.

A partir dos anos 70, o Poder Judiciário, ampliou sua presença na sociedade e na política, como forma de garantia de direitos, resultando numa explosão das discussões. O direito invade o social para garantir proteção aos mais vulneráveis. O cidadão passou a utilizar-se dos recursos criados pelo legislador, como vias alternativas para a defesa e eventuais conquistas de direitos ${ }^{10}$.

Este fenômeno foi denominado de judicialização por Tate e Vallinder, em 1995, em estudo sobre as relações do poder judiciário e a políti$\mathrm{Ca}^{11}$. Genericamente, pode-se considerar a judicialização como fenômeno constituído pela influência do Poder Judiciário nas instituições políticas e sociais ${ }^{12}$.

No Brasil, este fenômeno ganhou força na década de 90, com pacientes contaminados pelo vírus da síndrome de imunodeficiência adquirida (HIV) que se uniram através de Organizações Não Governamentais (ONG) ou outras associações criadas na sua defesa para, coletivamente, pleitearem novos medicamentos e tratamentos. A liminar julgada favorável, em 25 de julho de 1996, movida pelo Grupo de Apoio à Prevenção à Síndrome de Imunodeficiência Adquirida (AIDS) (GAPA-SP) contra o Estado de São Paulo, para fornecimento gratuito de medicamentos pelo Poder Público foi o marco inicial. A decisão abriu precedente para ajuizamento de outras demandas. Em 2001, as ações tiveram grande impacto no orçamento e no Programa Estadual de Doenças Sexualmente Transmissíveis (DST/AIDS) de São Paulo².

Uma crítica recorrente ao direito à saúde é que ele não seria passível de ser reclamado judici- 
almente. Esta perspectiva se tomada como verdadeira, estaria negando qualquer qualidade de legalidade aos direitos sociais e econômicos, reservando esta característica apenas para os direitos civis e políticos tradicionais ${ }^{13}$.

O fenômeno da Judicialização da Saúde vem crescendo de forma vertiginosa e a cada ano há incremento das ações contra o Poder Público ${ }^{14}$. As decisões dos processos podem ser favoráveis aos cidadãos, obrigando os sistemas de saúde a arcarem com a viabilização dos direitos, que nem sempre significam benefícios para o próprio indivíduo, mas podem acarretar desequilíbrios sociais. Uma revisão sistemática sobre o tema mostrou que a maioria dos estudos tem abrangência local e está concentrada na discussão da assistência farmacêutica. A maioria dos estudos centralizou atenção em estados do Sul e Sudeste, especialmente São Paulo e um número reduzido incluiu o Nordeste ${ }^{15}$.

Este estudo teve como foco a descrição e a análise dos registros de três tribunais brasileiros quanto às características das ações relacionadas ao Sistema Único de Saúde (SUS) e quanto aos resultados dessas ações.

\section{Metodologia}

É um estudo transversal, com base em dados secundários, obtidos nos acórdãos dos Tribunais de Justiça dos estados de Minas de Gerais (TJMG), Rio Grande do Sul (TJRS) e Pernambuco (TJPE), disponíveis nos sítios eletrônicos dos respectivos tribunais. Foram incluídos acórdãos referentes ao ano de 2009, cujas ementas constavam dados relativos ao SUS e a condenação ou absolvição de cumprimento de uma obrigação ao usuário.

Os três estados foram escolhidos por conveniência, buscando-se representação de três regiões distintas do Brasil: Sul (RS), Sudeste (MG) e Nordeste (PE). Optou-se pela segunda instância por serem estas decisões disponibilizadas por meio eletrônico. Além disso, a pesquisa se restringiu, mesmo nesta instância, às decisões colegiadas dos tribunais.

O cálculo amostral foi feito pelo método de estimativa de proporções, para amostra finita, segundo o total de acórdãos disponíveis em cada sítio, considerando a prevalência de eventos de $50 \%$, erro de 5\% e significância de 95\%. Obtevese o total da amostra, após acerto final, de 283 para Minas Gerais $(M G)(n=1.681)$ e 256 para o Rio Grande do Sul (RS) $(\mathrm{n}=1.000)$.
O total de acórdãos do RS para o ano de 2009 foi de 3.464. No entanto, a correção foi feita para 1000 decisões, total disponibilizado no sítio do tribunal, via internet. Em Pernambuco (PE), em função do número de acórdãos disponíveis, foi considerado o universo, 86 unidades de análise. As palavras-chave para pesquisa dos acórdãos foram: SUS e direito à saúde. Houve substituição dos acórdãos sorteados que não continham objeto de interesse para análise, como os de caráter previdenciário ou ressarcimentos de danos, pelo imediatamente seguinte até o limite do próximo sorteado.

A seleção dos acórdãos foi feita por meio de tabela de números randômicos, construída no programa Microsoft Office Excel 2007, para cada estado.

Utilizou-se, para a coleta de dados, um formulário elaborado para este fim. As variáveis coletadas foram: tipo de ação (ordinária, mandado de segurança, ação civil pública, ação cautelar inominada); representação jurídica do autor (Defensoria Pública, Ministério Público ou advogado particular e ONG); condição econômico-financeira alegada pelo autor (justiça gratuita, hipossuficiente economicamente); titularidade da ação (individual, coletiva ou individual e coletiva, pedido se fundamentado em um paciente mas pedia a extensão a outros com a condição semelhante); existência de pedido liminar (antecipação de tutela ou liminar); decisão do pedido liminar (deferimento ou indeferimento); existência de fundamentação da urgência e emergência alegada no pedido; resultado em segunda instância (favorável ao usuário, ao SUS ou usuário-SUS) e o tipo de recurso julgado. Advogados, Ministério Público e Defensoria poderiam ser considerados representantes de ações tanto individuais como coletivas, de acordo com o descrito na ação.

Considerou-se não informado julgamentos que se extinguiram sem resolução do mérito, por perda da necessidade de decisão, por exemplo, pela morte do demandante.

Os dados foram analisados empregando-se o Software Package for Social Sciences (SPSS for Windows, version 17.00), sendo submetidos à análise descritiva, com obtenção de frequência absoluta e relativa. A comparação entre tribunais dos três estados quanto às características das ações e quanto aos seus resultados foi realizada pelo teste qui-quadrado ou exato de Fisher, considerando-se nível de significância de 5\%.

A coleta de dados foi feita em banco público, disponibilizado pela internet, o que dispensa 
aprovação de projeto em comitês de ética em pesquisa, sem prejuízo do respeito às normas.

\section{Resultados}

Foram analisados 558 acórdãos, sendo 282 de MG representando $99,6 \%$ da amostra para esse estado, 222 do RS (86,7\%) e 54 (62,8\%) de Pernambuco.

Os tipos de ações mais frequentes foram as ordinárias $(73,1 \%)$, seguidas dos mandados de segurança $(19,9 \%)$. Houve maior frequência de ações ordinárias no TJRS e de mandado de segurança nos TJMG e TJPE (Tabela 1).

O principal recurso que levou a análise da decisão em segunda instância foi a apelação $(52,8 \%)$ (incluídas decisões revistas em grau de reexame necessário), seguido pelo agravo de instrumento $(38,4 \%)$. Os agravos internos e embargos de declaração apareceram em 4,8\% e 4,0\% dos acórdãos, respectivamente.

Quanto ao representante jurídico do autor, na maior parte havia ausência dessa informação $(54,5 \%)$; sendo maior a falta desse registro no
TJMG. Nos acórdãos identificados, observou-se que a Defensoria representou a maior parte das ações $(71,5 \%)$, sendo mais frequente no TJRS (Tabela 1).

Do total de ações analisadas, 61,6\% solicitaram antecipação de tutela e 22,2\% requereram outras liminares. A frequência de solicitação de antecipação de tutela foi maior no TJRS e a de liminar foi maior no TJMG e TJPE. Os pedidos liminares foram concedidos na maioria das ações (91,2\%), com percentual de indeferimento significativamente maior no TJMG e TJRS (Tabela 2).

A existência de fundamentação da decisão na urgência e emergência alegada no pedido foi encontrada na maioria das ações $(81,2 \%)$, independentemente do tribunal analisado (TJMG = $79,8 \% ;$ TJRS $=80,2 \% ;$ TJPE $=92,6 \%)(p=0,56)$.

Quanto ao resultado dos recursos em segunda instância, houve predominância de favoráveis aos usuários $(97,8 \%)$. Um maior número de favoráveis ao SUS $(20,2 \%)$ e favorável a ambos $(4,3 \%)$ foi observado em MG, se comparado com os outros dois estados (Tabela 3). Nos favoráveis aos usuários $(\mathrm{n}=481)$, houve maior frequência de ações ordinárias no RS (58,2\%) compa-

Tabela 1. Frequência e comparação das características das ações demandadas de acordo com Tribunais de Justiça de Minas Gerais (TJMG), do Rio Grande do Sul (TJRS) e de Pernambuco (TJPE).

\begin{tabular}{|c|c|c|c|c|c|c|c|c|}
\hline \multirow{3}{*}{ Características da ação } & \multicolumn{6}{|c|}{ Tribunal } & & \\
\hline & \multicolumn{2}{|c|}{ TJMG } & \multicolumn{2}{|c|}{ TJRS } & \multicolumn{2}{|c|}{ TJPE } & \multicolumn{2}{|c|}{ Total } \\
\hline & $\mathbf{n}^{\circ}$ & $\%$ & $\mathrm{n}^{\circ}$ & $\%$ & $\mathbf{n}^{\circ}$ & $\%$ & $\mathbf{n}^{\circ}$ & $\%$ \\
\hline \multicolumn{9}{|l|}{ Tipo de ação } \\
\hline Ação ordinária & 178 & 63,1 & 210 & 94,6 & 20 & 37,0 & 408 & 73,1 \\
\hline Mandado de segurança & 85 & 30,1 & 1 & 0,5 & 25 & 46,3 & 111 & 19,9 \\
\hline Ação civil pública & 19 & 6,7 & 11 & 5,0 & 8 & 14,8 & 38 & 6,8 \\
\hline Ação cautelar inominada & 0 & 0 & 0 & 0 & 1 & 1,9 & 1 & 0,2 \\
\hline \multicolumn{9}{|c|}{ * Diferença com significância estatística dos três tribunais entre si $(\mathrm{p}<0,05)$} \\
\hline \multicolumn{9}{|l|}{ Representante jurídico do autor ${ }^{*}$} \\
\hline Defensoria pública & 37 & 46,8 & 138 & 90,2 & 8 & 33,3 & 183 & 71,5 \\
\hline Advogado particular & 16 & 20,3 & 2 & 1,3 & 2 & 8,3 & 20 & 7,8 \\
\hline Ministério público & 26 & 32,9 & 13 & 8,5 & 12 & 50,0 & 51 & 19,9 \\
\hline Organização não-governamental & 0 & 0 & 0 & 0 & 2 & 8,3 & 2 & 0,8 \\
\hline \multicolumn{9}{|c|}{${ }^{*}$ Diferença com significância estatística dos três tribunais entre si $(\mathrm{p}<0,05)$} \\
\hline \multicolumn{9}{|c|}{ Titularidade das accões } \\
\hline Individual & 274 & 97,2 & 221 & 99,5 & 51 & 94,4 & 546 & 97,8 \\
\hline Coletiva & 5 & 1,8 & 1 & 0,5 & 3 & 5,6 & 9 & 1,6 \\
\hline Individual e coletiva & 3 & 1,1 & 0 & 0 & 0 & 0 & 3 & 0,5 \\
\hline
\end{tabular}

Nota: ausência de dados sobre propositura da ação em 203 acórdãos do TJMG, 69 no TJRS e 32 no TJPE. 
Tabela 2. Resultados dos pedidos de liminares e das concessões de pedidos nos tribunais de Minas Gerais, Rio Grande do Sul e Pernambuco, 2009.

\begin{tabular}{|c|c|c|c|c|c|c|c|c|}
\hline & \multicolumn{6}{|c|}{ Tribunal } & & \\
\hline & \multicolumn{2}{|c|}{ TJMG } & \multicolumn{2}{|c|}{ TJRS } & \multicolumn{2}{|c|}{ TJPE } & \multicolumn{2}{|c|}{ Total } \\
\hline & $\mathbf{n}^{\circ}$ & $\%$ & $\mathbf{n}^{\circ}$ & $\%$ & $\mathbf{n}^{\circ}$ & $\%$ & $n^{\circ}$ & $\%$ \\
\hline \multicolumn{9}{|l|}{ Pedido liminares } \\
\hline Antecipacao de tutela & 156 & 55,3 & 166 & 74,8 & 22 & 40,7 & 344 & 61,6 \\
\hline Liminar & 76 & 27,0 & 19 & 8,6 & 29 & 53,7 & 124 & 22,2 \\
\hline Não informado & 50 & 17,7 & 37 & 15,7 & 3 & 5,6 & 90 & 16,1 \\
\hline \multicolumn{9}{|c|}{${ }^{*}$ Diferença com significância estatística dos três tribunais entre si $(\mathrm{p}<0,05)$} \\
\hline Concessão de pedidos & 204 & 88,3 & 171 & 92,4 & 51 & 100 & 426 & 91,2 \\
\hline Deferida & 26 & 11,3 & 12 & 6,5 & 0 & 0 & 38 & 8,1 \\
\hline Indeferida & 52 & 0,4 & 39 & 1,1 & 3 & 0 & 94 & 0,7 \\
\hline \multicolumn{9}{|l|}{ Não informado } \\
\hline${ }^{*}$ Diferença & ância & estatís & TJPE & para & MG & TJR & & \\
\hline
\end{tabular}

Tabela 3. Resultados das ações em segunda instância nos tribunais de Minas Gerais, Rio Grande do Sul e Pernambuco, 2009.

\begin{tabular}{|c|c|c|c|c|c|c|c|c|}
\hline \multirow[t]{2}{*}{ Resultado em $2^{\text {a }}$ Instância } & \multicolumn{2}{|c|}{ TJMG } & \multicolumn{2}{|c|}{ TJRS } & \multicolumn{2}{|c|}{ TJPE } & \multicolumn{2}{|c|}{ Total } \\
\hline & $n^{\circ}$ & $\%$ & $\mathbf{n}^{\circ}$ & $\%$ & $\mathbf{n}^{\circ}$ & $\%$ & $\mathbf{n}^{\circ}$ & $\%$ \\
\hline Favorável usuário & 212 & 75,2 & 217 & 97,7 & 52 & 96,3 & 481 & 97,8 \\
\hline Favorável SUS & 57 & 20,2 & 4 & 1,8 & 0 & 0 & 61 & 1,6 \\
\hline Favorável SUS e usuário & 12 & 4,3 & 1 & 0,5 & 1 & 1,9 & 14 & 0,5 \\
\hline Não informado & 1 & 0,4 & 0 & 0 & 1 & 1,9 & 2 & 0,1 \\
\hline
\end{tabular}

* Diferença com significância estatística do TJMG para o TJRS e TJPE $(\mathrm{p}<0,05)$

rativamente a $\mathrm{MG}(36,4 \%)$ e $\mathrm{PE}(5,4 \%)$ e maior frequência de ações do tipo mandado de segurança em MG $(73,7 \%)$ comparativamente ao RS $(1,1 \%)$ e PE $(25,3 \%)(p=0,000)$. Entre os resultados favoráveis ao SUS e ao Usuário-SUS, não foi observada diferença significativa na distribuição da frequência dos tipos de ações entre os tribunais $(\mathrm{p}>0,05)$.

\section{Discussão}

Os resultados deste estudo mostraram que, de modo geral, houve variabilidade nas ações que envolviam a saúde pública e nas decisões judiciais entre os tribunais de justiça dos estados de $\mathrm{MG}, \mathrm{RS}$ e PE.

O estudo obteve resultados satisfatórios nos três tribunais, não alcançou a amostra calculada pela limitação da reposição de perdas. Nos dados de PE, não foi possível reposição das perdas por ser análise do universo. Considerando-se o número total de acórdãos no ano de 2009, houve diferença entre os três tribunais, desproporcional à população de cada estado. O maior número de ações encontradas foi no estado do RS (3.464), que possuía, em 2009, aproximadamente $10 \mathrm{mi}$ lhões de habitantes, quase a metade da população de MG (19 milhões de habitantes), com um total de 1.681 acórdãos no mesmo período. Já Pernambuco ( 8 milhões de habitantes) apresentou 86 acórdãos, número bem inferior aos demais estudados. Estes dados sugerem maior procura pelo Poder Judiciário para o direito à saúde no RS e que outros fatores, além do tamanho da população, podem ter influenciado essa procura.

Contudo, como foram analisados tribunais de segunda instância, essa comparação entre os 
estados pode não refletir a demanda real, pois a análise incluiu apenas decisões onde houve recurso pela parte sucumbente na primeira instância de julgamento, procurando revisão da decisão e segundo julgamento, ou nos casos de reexame necessário. Portanto, esta limitação permeia todos os resultados apresentados. Adicionalmente, uma discussão da diferença acerca da procura pela efetivação dos direitos à saúde pela população dos três estados deveria incluir também o cenário da saúde suplementar.

No entanto, esses estados apresentam diferenças socioeconômicas e culturais que poderiam justificar os resultados encontrados. Há características específicas em relação aos tipos de doenças e agravos mais prevalentes ${ }^{16,17}$ e o acesso aos serviços de saúde ${ }^{17,18}$. Este acesso, melhor nas regiões Sul e Sudeste apresenta piores índices nas regiões Norte e Nordeste. Interessante ressaltar, que há discrepâncias socioeconômicas não só entre as regiões, mas também internamente. Um exemplo é a região Sul, uma das mais desenvolvidas do país, mas com maior desigualdade social ${ }^{19}$.

Em alguns estados, como os pedidos judiciais estão aumentando, os serviços de saúde estão se organizando para acompanhar o perfil das demandas. Há relatos deste acompanhamento entre os estados estudados, $\mathrm{MG}^{14}$ e $\mathrm{RS}^{20}$, sendo também identificadas iniciativas em São Paulo ${ }^{21}$. Não foi possível identificar que o mesmo ocorra no estado de Pernambuco. A baixa frequência de ações encontradas na segunda instância ou a falta de pesquisa nesta região do país são possíveis explicações para este achado.

Ao comparar os tribunais e as ações, verificou-se que as ações ordinárias foram mais prevalentes no TJRS e os mandados de segurança no TJMG e TJPE. Interessante ressaltar que o tipo de ação mais frequente em MG e no RS foi a de maior frequência de resultados favoráveis aos usuários no tribunal correspondente, efeito não observado entre os resultados favoráveis ao SUS. Este fato sugere haver predisposição de resultado favorável ao usuário relacionado ao tipo de ação escolhida e o tribunal no qual será impetrada. Estudos específicos poderiam avaliar melhor as causas e consequências deste resultado, se há influência nesta escolha pelos representantes jurídicos dos pacientes nos estados citados, baseada na jurisprudência de cada tribunal.

A opção pela ação ordinária justifica-se pela possibilidade de produzir provas durante o processo, por exemplo, através de receitas, atestados médicos ou perícia, para comprovar o pedido realizado e, caso tenha uma necessidade premen- te de receber a prestação, há a possibilidade de pedir antecipação de tutela. Nos mandados de segurança, o paciente busca intervenção rápida do poder judiciário, no entanto, as provas que comprovam o pedido devem ser demonstradas no momento da propositura da ação ${ }^{22}$. A ação civil pública reveste-se da particularidade da representação ser específica, só podendo ser feito pelo Ministério Público (MP), Defensoria e Associações, destinando-se à defesa de direitos específicos ${ }^{23}$. A escolha do tipo de ação é decisão a ser tomada em conjunto entre representante jurídico do autor e o próprio autor, de acordo com expectativas e características do direito pleiteado.

Houve predomínio de ações com representação jurídica da Defensoria Pública. Resultados semelhantes foram encontrados no Rio de Janeiro $^{24,25}$ e no Distrito Federal ${ }^{24}$. Em alguns estados, a Defensoria e o MP são mais atuantes. Em estudos nos quais se verificou um predomínio da representação da Defensoria Pública, relata-se que a comprovação da hipossuficiência da pessoa é requisito para propositura da ação por este órgão e a condição socioeconômica é avaliada no caso concreto. Em outros, como São Paulo, MG e RS, um critério para o acesso à Defensoria é a renda familiar que deve ser, no máximo, de três salários mínimos ${ }^{24}$.

A participação da Defensoria no RS foi maior, estado este com significativo número de hipossuficientes informados. Este fato pode ser explicado pela posição atuante da Defensoria no estado, que facilitaria o acesso dos menos favorecidos para pleitear seus pedidos. O MP tem participação destacada em Pernambuco (50,0\%), assim como a Defensoria (33,3\%).

$\mathrm{O}$ acesso à justiça é condição imprescindível para o exercício dos direitos de cidadão. Neste sentido, a assistência judiciária é garantida ao hipossuficiente, economicamente, considerado pela lei, no art. $2^{\circ}$ como "aquele cuja situação econômica não lhe permita pagar custas processuais e honorários de advogado, sem prejuízo do sustento próprio ou da família"26. A Constituição Federal procura promover legalmente esta assistência $^{7}$ aos que comprovarem insuficiência de recursos, considerando além da defensoria, o MP e a advocacia pública como funções essenciais ao acesso à Justiça por a viabilizarem ${ }^{27}$.

Portanto, apesar dos questionamentos, é comum encontrar ações civis públicas propostas pelo MP na defesa do interesse de um único paciente ou de um grupo determinado e restrito, baseado na capacidade conferida pela Constituição Federal, que lhe atribuiu legitimidade para de- 
fender direitos individuais indisponíveis, como o direito à saúde. Dentro dos limites legais, esta prática pode ser um caminho eficiente no combate à ineficácia do Poder Público na implementação de políticas públicas, podendo beneficiar segmentos sociais hipossuficientes ${ }^{28}$.

No total dos acórdãos nos quais foi possível verificar o representante, a participação de advogados particulares foi pequena, achado semelhante ao descrito no Distrito Federal ${ }^{15}$; por outro lado, em desacordo com o predomínio da condução das ações por advogados particulares encontrado no estado de São Paulo ${ }^{29}$, Santa Ca$\operatorname{tarina}^{30}$ e $\mathrm{MG}^{31}$.

Uma possível explicação para este achado é que a maioria dos estudos concentra em pedidos de medicamentos, diferentemente deste e do realizado no Distrito Federal, que analisou qualquer tipo de demanda. Como para a propositura de uma ação, o indivíduo necessita, obrigatoriamente, estar representado juridicamente, este dado sugere que usuários do SUS que buscam o Poder Judiciário o fazem com apoio no próprio Poder Público, ou seja, através da Defensoria ou MP.

No presente estudo, a falta de dados sobre a situação econômica dos demandantes das decisões analisadas não permitiu avaliar se eram hipossuficientes ou se foi concedido a eles o benefício da justiça gratuita, impossibilitando discutir a situação de vulnerabilidade social. A variável foi incluída no estudo como de interesse pelo fato de alguns autores discutirem se a judicialização da saúde estaria priorizando os que podem arcar com os custos de um processo ${ }^{14}$, atendendo, portanto, a pessoas que teriam condições de pagar pelo tratamento pleiteado ${ }^{12,29,31-33} \mathrm{e}$, assim, o Judiciário estaria agravando a situação dos menos favorecidos. No entanto, embora não se possa dizer com certeza que quem procura um advogado particular pode realmente arcar com os custos de tratamento em saúde, pode-se dizer que a afirmação contrária leva a um dado confiável, ou seja, pode-se considerar que quem recorreu ao Poder Público, como forma de viabilizar o acesso ao Poder Judiciário, não pertence a uma classe mais favorecida ${ }^{15}$.

Há ainda a possibilidade do cidadão, mesmo sendo hipossuficiente, procurar a justiça utilizando-se de advogados particulares, pois a remuneração de um advogado privado pode ser relativamente baixa ou pode haver parceria entre o Poder Público e advogados privados para a atuação jurídica ${ }^{15}$.

O que deve ser considerado na análise é se o cidadão poderia dispor do valor para custear as despesas judiciais sem comprometer a sua subsistência e a de sua família, o que é um dado relativo ao valor do tratamento do qual se necessita e a renda familiar. Esta variável já foi utilizada em outro estudo, que considerou que aqueles que eram beneficiários da justiça gratuita eram considerados hipossuficientes economicamente, tendo sido encontrado que a concessão da justiça gratuita e, consequentemente, o reconhecimento da hipossuficiência econômica é característica majoritária nas demandas por medicamentos ${ }^{9}$.

No entanto, as comparações e as discussões quanto à representação jurídica das ações e sua relação com a condição de hipossuficiência precisam ser avaliadas com cuidado, devendo ser confirmadas por outros estudos, considerandose a alta proporção de ações com ausência de informações sobre esta representação e sobre a condição socioeconômica.

Nos três tribunais estudados, as ações foram propostas predominantemente de forma individual, com baixa frequência de ações coletivas. Estes resultados conduzem à reflexão sobre a possibilidade de aumento das desigualdades em função de privilégios individuais contrapondose o direito à vida e à saúde na esfera individual e na coletiva. Há um questionamento se o gasto de recursos para atender de forma individualizada aos pedidos poderia gerar falta de recurso para o suprimento das necessidades coletivas. Como o gasto com a saúde pública no Brasil é aquem do necessário, parece-nos ser este um argumento simplista com que os gestores do orçamento da saúde tentam justificar o não atendimento de uma demanda individual.

Nesse sentido, o direito individual poderia ser considerado um obstáculo às necessidades de toda a população, constituindo um equívoco considerar o não fornecimento de determinado serviço como mitigação do próprio direito à saú$\mathrm{de}^{34}$. As leis enfatizam mais o direito individual à saúde, entretanto, este deveria ser considerado levando-se em conta a coletividade. A existência de um direito à saúde individual leva ao questionamento de como pesar o direito de um indivíduo contra o do outro, ou como resolver o conflito de direitos ${ }^{13}$.

Sob a ótica de um indivíduo, que se encontra doente, com uma necessidade urgente, considera-se que a sua demanda deve ser atendida de forma integral e com celeridade, pois há, para o mesmo, a possibilidade de sofrer com o descaso ou com a ineficiência do Estado em cumprir com as suas obrigações legais de garantias ao direito à saúde e à vida. Esperar um sacrifício de sua inte- 
gridade física ou mesmo de sua vida, em prol dos direitos coletivos, não seria uma atitude factível em termos de conduta individual'.

Não há dúvidas que o direito à saúde compreende o plano coletivo e o individual. No individual, implicaria a possibilidade de escolhas distintas e alternativas, entre elas, os recursos a serem procurados e o tipo de tratamento a ser submetido. No coletivo, remete-se à garantia da oferta de cuidados da saúde dos quais todos necessitam, o que corresponde ao ideal de igualdade e que, por sua vez, se submete ao pleno desenvolvimento do Estado ${ }^{35}$.

O argumento da existência do direito à saúde, especialmente o individual, reveste-se de uma importância singular para o Judiciário, que tem o dever de decidir quando solicitado, quase sempre em situação de prestações de cunho emergencial, cujo indeferimento acarretaria o comprometimento irreversível ou mesmo o sacrifício de outros bens essenciais, como a vida, a integridade física e a dignidade da pessoa humana ${ }^{36}$. Há a argumentação de que indeferimento de uma prestação referente à saúde por falta de recursos poderia ser comparado ao de condenar, mesmo que indiretamente, uma pessoa à morte, pena esta proibida no ordenamento jurídico brasileiro ${ }^{36}$.

Frente aos fatos e considerando a teoria da justiça distributiva, o poder judiciário tem considerado como parâmetro mais justo, o princípio da necessidade descrito por Deutsch em 1975, tendendo a se preocupar com a promoção do bem estar do indivíduo. No entanto, em um país marcado pelas injustiças, existe a necessidade de se compreender a associação entre o julgamento de justiça, o comportamento distributivo e o desenvolvimento sociomoral, como forma de um maior entendimento da dinâmica da vida social ${ }^{37}$.

Houve uma pequena frequência de ações com representação jurídica com a participação de ONG. Assim, a participação dessas organizações, que foram tão importantes para o surgimento e o fortalecimento do processo de judicialização da saúde no Brasil ${ }^{2}$, parecem ter perdido força e já não são tão procuradas pelo usuários ${ }^{15}$. Conclui-se que o perfil dos demandantes já não é o mesmo do início do fenômeno, quando houve uma mobilização de pessoas com os mesmos interesses. Os usuários têm preferido a solicitação individual dos pedidos à procura de associações para a defesa de seus direitos, sem uma preocupação com a coletividade.

O indivíduo, quando procura a via judicial, seja pela urgência do agravo a saúde ou pela demora já apresentada pelos serviços, deseja rápi- da satisfação de suas necessidades, fato comprovado pelo alto número de pedidos liminares. Neste estudo, foi encontrada uma grande porcentagem de deferimento desses pedidos, nos três estados. Percentual alto de concessão de tutela foi também observado no Rio de Janeiro (96,9\% das ações) $)^{9}$, Distrito Federal $(91,95 \%)^{15}$ e em São Paulo $(93,5 \%)^{38}$.

As decisões estão fundamentadas na descrição de situações que levam o Judiciário a acreditar em prejuízo na demora de concessão de uma determinada prestação. Entretanto, muitas vezes a medida torna-se irrevogável pelo cumprimento, por exemplo, no caso de intervenções cirúrgicas, tornando também irreversível o dano causado ao orçamento do ente estatal. Nas decisões quanto à concessão de antecipação de tutela, o principal critério judicial seria a constatação da necessidade do demandante em ter acesso urgente a determinado medicamento ou procedimento, tendo como respaldo os documentos fornecidos pelo demandante, em geral, os receituários médicos ${ }^{9,24}$. O tribunal de Minas Gerais e o do Rio Grande do Sul se mostraram mais conservadores na concessão desses pedidos, com o maior percentual de pedidos indeferidos, fator que pode ser mais uma vez explicado pela aproximação dos serviços públicos de saúde e de justiça ${ }^{14,20,21,29}$.

Neste estudo, observou-se a alegação de urgência e emergência em quase totalidade das ações com solicitação de pedidos liminares. Resultados semelhantes foram encontrados em Minas Gerais $^{14}$, São Paulo ${ }^{39} \mathrm{e}$ Distrito Federa ${ }^{15}$, com alto percentual de concessão dos pedidos de liminares usando como fundamento a urgência do pedido, em face da possibilidade de se causar dano irreversível à saúde do demandante.

$O$ conceito de urgência e emergência, definido pelo Conselho Federal de Medicina, considera a urgência como a "ocorrência imprevista de agravo à saúde com ou sem risco potencial de vida, cujo portador necessita de assistência médica imediata" e emergência "a constatação de condições de agravo à saúde que impliquem risco iminente de vida ou sofrimento intenso, exigindo, portanto, tratamento médico imediato" 40 . Se nem mesmo neste conceito fica realmente fácil definir e diferenciar uma condição da outra, podese imaginar o que acontece com a percepção de um usuário e de um juiz ou desembargador no momento de emitir uma decisão. Como os próprios profissionais de saúde não têm a clara noção destes conceitos, o usuário vai utilizá-los de acordo com a necessidade ou percepção a respeito do seu próprio estado de saúde e sua experiên- 
cia de vida ${ }^{41}$. O mesmo, possivelmente, é o que acontece com o julgador ao proferir sua decisão no processo. Neste estudo, observou-se que, para a maioria das ações nas quais foi alegada urgência e emergência, houve o deferimento destes pedidos liminares, independentemente do tribunal.

Enquanto a concessão da medida liminar pode causar danos ao erário, o indeferimento poderia causar um comprometimento irreversível da saúde, integridade física, dignidade da pessoa humana e, muitas vezes, da própria vida do cidadão. A urgência/emergência por si só pode acarretar resultados que podem ser desfavoráveis, tanto para o usuário como para o SUS, sobretudo pela exígua discussão do caso.

O maior número de decisões foi favorável aos usuários nos três estados, o que se assemelha ao observado em São Paulo, onde 90,3\% das ações foram julgadas como procedentes, ou seja, os demandantes, pacientes do SUS, obtiveram a prestação pretendida na maioria das vezes ${ }^{38}$. No presente estudo, houve ainda um pequeno número no qual os desembargadores optaram por conceder o pedido de forma parcial, o que foi considerado como favorável a ambos. $\mathrm{O}$ estado de $\mathrm{Mi}$ nas Gerais apresentou mais decisões favoráveis ao SUS ou de concessão parcial do pedido frente aos outros dois estados estudados, sugerindo uma diferença de posicionamento nas decisões de acordo com o tribunal avaliado. Há ainda que se ponderar o fato do TJRS ser conhecido como um tribunal de vanguarda, muitas vezes proferindo decisões inéditas entre os tribunais brasileiros ${ }^{42}, \mathrm{o}$ que poderia explicar, em parte, algumas destas diferenças encontradas neste estudo.

Este dado deve ser analisado com mais profundidade, pois sugere que fatores como o tipo de ação mais frequente no estado e o perfil socioeconômico do demandante podem estar interferindo nos resultados.

O fenômeno de judicialização da saúde é uma realidade para ambos, Poder Judiciário e Sistema Único de Saúde. A participação da Defensoria e do MP parece estar viabilizando o acesso aos processos judiciais. Embora o processo de judicialização tenha começado de forma coletiva no país, o que se observa atualmente é que o cidadão tem buscado de forma individual garantir seu direito à saúde, mesmo que recorrendo ao próprio Poder Público como forma de auxílio no processo. Os tribunais estudados demonstram que há uma forte tendência do Judiciário em acolher as solicitações de prestações feitas ao Sistema Único de Saúde, inclusive com concessões de liminares fundamentando-se, muitas vezes, na urgência/emergência da necessidade da prestação, acreditando evitar, desta maneira, que o usuário possa sofrer algum dano irreversível pela demora na prestação.

\section{Considerações Finais}

No estudo realizado, baseado nos recursos julgados em segunda instância de ações impetradas contra os serviços públicos de saúde, evidenciaram-se diferenças entre os estados quanto ao tipo da ação demandada e a participação do poder público na representação jurídica dessas ações. Os resultados sugerem maior acesso ao poder judiciário e maior representação pela defensoria pública no Estado do Rio Grande do Sul. Este Estado, juntamente com Pernambuco, apresentou maior frequência de resultados favoráveis aos usuários comparativamente a Minas Gerais.

O maior número de decisões favoráveis aos usuários pode interferir e modificar os sistemas de saúde, em especial o Sistema Único de Saúde, cenário deste estudo. O poder judiciário funcionando como guardião, com base na Constituição tem possibilitado essas mudanças, que precisam, no entanto, ser refletidas criticamente. E o princípio da equidade deve permear essas reflexões.

As diferenças entre decisões dos tribunais de justiça devem ser estudadas com finalidade de se compreender as características regionais de acesso aos serviços tanto de saúde como os relacionados ao poder judiciário, da eficiência na prestação dos serviços públicos, posturas dos profissionais de saúde e gestores locais e ainda do conhecimento e da capacidade de exercício dos direitos, garantidos por lei, por parte da população, bem como valores e concepções utilizados pelos juízes no julgamento dos recursos.

Reforça-se a necessidade de estudos que contemplem não somente a dimensão do "judiciário", mas que incluam nessa discussão valores distributivos e o comportamento moral da sociedade. 


\section{Colaboradores}

DV Travassos foi responsável pela coleta de dados. RC Ferreira foi responsável pela revisão estatística, análise dos dados e revisão do trabalho. Os demais autores participaram em conjunto na concepção, redação, análise dos dados e revisão do trabalho.

\section{Referências}

1. Silva BMP. O sistema Único de Saúde: descompasso entre realidade normativa e realidade fática [tese]. São Paulo: Pontifícia Universidade Católica de São Paulo; 2007.

2. Brasil. Ministério da Saúde (MS). Secretaria de Vigilância em Saúde. Programa Nacional de DST e Aids. O Remédio via Justiça: um estudo sobre o acesso a novos medicamentos e exames em HIV/ aids no Brasil por meio de ações judiciais. Brasília: MS; 2005

3. World Health Organization (WHO). The Rigth to health. Genebra: WHO; 2008.

4. Braveman O, Gruskin P. Poverty, equity, human rights and health. Bull World Health Organ 2003; 81(7):539-545.

5. Barroso AF. Aspectos Relacionados À Efetivação Do Direito À Saúde No Brasil Através Do Poder Judiciário [monografia]. Rio de Janeiro: ENSP, Fiocruz; 2003.

6. Brasil. Ministério da Saúde (MS). Manual de direito sanitário com enfoque na vigilância em saúde. Brasília: MS; 2006.

7. Brasil. Constituição da República Federativa do Brasil de 1988. Diário Oficial da União 1988; 5 out.

8. Street Junior RL, Haidet P. How well do the doctors Know their patients? Factors affecting physician undertstanding of patients' health beliefs. J Gen Intern Med 2011; 26(1):21-27.

9. Ventura MSL, Pepe VLE, Schramm FR. Judicialização da saúde, acesso à justiça e a efetividade do direito à saúde. Physis 2010; 20(11):77-100.

10. Vianna LW, Burgos MB, Salles PM. Dezessete anos de judicialização da política. Tempo soc 2007; 19(2):39-85.

11. Carvalho ER. Em busca da judicialização da política no Brasil: apontamentos para uma nova abordagem. Rev Sociol Polit 2004; 23:127-139.

12. Borges DCL, Ugá MAD. As ações individuais para o fornecimento de medicamentos no âmbito do SUS: características dos conflitos e limites para a atuação judicial. Rev Direito Sanit 2009; 10(1):13-38.

13. Chinkin C. Health and Human Rights. Public Health 2006; 120(Supl.):52-60

14. Marques ORA, Melo MB, Santos APS. Ações Judiciais no âmbito do Sistema Único de Saúde do Brasil, Bases Legais e Implicações: um estudo de caso em um Tribunal da Região Sudeste. Rev Direito Sanit 2011; 12(1):41-66.

15. Penalva J. Judicialização do Direito à Saúde: O caso do Distrito Federal. Belo Horizonte: Faculdade de Filosofia e Ciências Humanas; 2010/2011.

16. Cesse EAP. Epidemiologia e Determinantes Sociais das Doenças Crônicas Não Transmissíveis no Brasil [tese]. Recife: Centro de Pesquisas Aggeu Magalhães, Fiocruz; 2007.

17. Zapponi ALB, Melo ECP. Distribuição da mortalidade por câncer de mama e de colo de útero, segundo regiões brasileiras. Rev Enferm 2010; 18(4): 628-631. 
18. Gutierrez MS. A oferta de tomógrafo computadorizado para o tratamento do acidente vascular cerebral agudo, no Brasil, sob o ponto de vista das desigualdades geográficas e sociais [dissertação]. Brasília: Escola Nacional de Saúde Pública Sérgio Arouca; 2009.

19. Travassos C, Oliveira EXG, Viacava F. Desigualdades geográficas e sociais no acesso aos serviços de saúde no Brasil: 1998 e 2003. Cien Saude Colet 2006; 11(4):975-986.

20. Picon PD. Ações judiciais e evidências científicas. In: Keinert TMM, Paula SHB de, Bonfim JRA, organizadores. As ações judiciais no SUS e a promoção do direito à saúde. São Paulo: Instituto de Saúde; 2009.

21. Filho MN, Chieffi AL, Correa MCMMA. S-Codes: um novo sistema de informações sobre ações judiciais da Secretaria de Estado da Saúde de São Paulo. Bepa 2010; 7(84):18-30.

22. Leyser MFVR. Mandado de segurança Individual e Coletivo. São Paulo: WVC Editora; 2002.

23. Brasil. Lei no 7.347 de 24 de julho de 1985. Disciplina a ação civil pública de responsabilidade por danos causados ao meio-ambiente, ao consumidor, a bens e direitos de valor artístico, estético, histórico, turístico e paisagístico dá outras providências. Diário Oficial da União 1985; 25 jul.

24. Edais VL, Ventura M, Sant'ana JMB, Figueiredo TA, Souza VR, Simas L. Caracterização de demandas judiciais de fornecimento de medicamentos "essenciais" no Estado do Rio de Janeiro, Brasil. Cad Saude Publica 2010; 26(3):461-471.

25. Messeder AM, Osorio-de-Castro CGS, Luiza VL. Mandados judiciais como ferramenta para garantia do acesso a medicamentos no setor público: a experiência do Estado do Rio de Janeiro, Brasil. Cad Saude Publica 2005; 21(2):525-534.

26. Brasil. Lei no 1.060 de 5 de fevereiro de 1950. Estabelece normas para a concessão de assistência judiciária aos necessitados. Diário Oficial da União 1950; 13 fev.

27. Oliveira SS. Defensoria pública brasileira: sua história. Revista de Direito Público 2007; 2(2):59-74.

28. Gandini JAD, Barione SF, Souza AE. A judicialização do direito à saúde: a obtenção de atendimento médico, medicamentos e insumos terapêuticos por via judicial - critérios e experiências. Academia Brasileira de Direito [periódico na Internet] $2008 \mathrm{Fev}$ [acessado 2012 jul 09]. Disponível em: http://abdir. com.bf/doutrina/ver.asp?id=1451\&categoria sanitário

29. Chieffi AL, Barata RCB. Ações judiciais: estratégia da indústria farmacêutica para introdução de novos medicamentos. Rev Saude Publica 2010; 44(3): 421-429.

30. Pereira JR, Santos RID, Nascimento Júnior JMD, Schenkel EP. Análise das demandas judiciais para o fornecimento de medicamentos pela Secretaria de Estado da Saúde de Santa Catarina nos anos de 2003 e 2004. Cien Saude Colet 2010; 15 (Supl. 3):3551-3560.
31. Machado MAA. Acesso a medicamentos via poder judiciário no Estado de Minas Gerais [dissertação]. Belo Horizonte: Universidade Federal de Minas Gerais; 2010

32. Vieira FS, Zucchi P. Distorções causadas pelas ações judiciais à política de medicamentos no Brasil. Rev Saude Publica 2007; 41(2):214-222.

33. Vieira FS. Ações judiciais e direito à saúde: reflexão sobre a observância aos princípios do SUS. Rev Saude Publica 2008; 42(2):365-369.

34. Gontijo, CD. A judicialização do direito à saúde. Rev Med Minas Gerais 2010; 20(4):606-611.

35. Nogueira VMR, Pires DEP. Direito à saúde: um convite à reflexão. Cad Saude Publica 2004; 20(3): 753-760.

36. Sarlet IW, Figueiredo MF. Algumas considerações em torno do conteúdo, eficácia e efetividade do direito à saúde na Constituição de 1988. Direitos Fundamentais e Justiça 2007; 1:171-213.

37. Sampaio LR, Camino, CPS, Roazzi, A. Justiça distributiva: uma revisão da literatura psicossocial e desenvolvimentista. Psicol Estud 2009; 14(4):631640 .

38. Marques SB, Dallari SG. Garantia do direito social à assistência farmacêutica no Estado de São Paulo. Rev Saude Publica 2007; 41(1):101-107.

39. Edais PVL, Figueiredo TA, Simas L, Osorio-deCastro CGS, Ventura M. A judicialização da saúde e os novos desafios da gestão da assistência farmacêutica. Cien Saude Colet 2010; 15(5):2405-2414.

40. Brasil. Conselho Federal de Medicina. Resolução $\mathrm{n}^{\circ} 1.451$ de 10 de março de1995. Diário Oficial da União 1995; 17 Mar.

41. Rocha AFS. Determinantes da Procura de Atendimento de Urgência pelos Usuários nas Unidades de Pronto Atendimento da Secretaria Municipal de Saúde de Belo Horizonte [dissertação]. Belo Horizonte: Universidade Federal de Minas Gerais; 2005.

42. Farpas separatistas: Presidente do TJ-RS critica presidente do TRF-3. Revista Consultor Jurídico 2009 Jun. [acessado 2012 jun 18]. Disponível em: http:/ /www.conjur.com.br/2009-jul-04/presidente-tj-rsresponde-criticas-presidente-trf

Artigo apresentado em 31/07/2012

Aprovado em 29/10/2012

Versão final apresentada em 13/11/2012 
